\title{
Effect of autoclave cycles on cyclic fatigue resistance of control memory NiTi files observed by scanning electron microscopy
}

\author{
Victor Talarico Leal Vieira, ${ }^{1}$ Hélio Pereira Lopes, ${ }^{2}$ Carlos Nelson Elias, ${ }^{3}$ Leticia Chaves de Souza, ${ }^{4}$ Emmanuel João Nogueira Leal da Silva, ${ }^{1}$ Daniel de Brito Prata, \\ ${ }^{1}$ Edson Jorge Lima Moreira, ${ }^{1}$ Marcia Valeria B. Vieira ${ }^{2}$ \\ 'Department of Endodontics, Faculty of Dentistry, Grande Rio University - UNIGRANRIO, Rio de Janeiro, RJ, Brazil \\ ${ }^{2}$ Department of Endodontics, Faculty of Dentistry, Estácio de Sá University -UNESA, Rio de Janeiro, RJ, Brazil \\ ${ }^{3}$ Department of Material Science, Military Institute of Engineering - IME, Rio de Janeiro, RJ, Brazil \\ ${ }^{4}$ Department of Endodontics, Faculty of Dentistry, Rio de Janeiro Federal University, Rio de Janeiro, RJ, Brazil \\ - Conflicts of interest: none declared.
}

\section{Abstract}

Objective: Hyflex CM instruments were developed for debridement of the root canal system. The control-memory alloy recovers its shape on sterilization, thereby allowing instrument reuse. This study investigated the effect of shape recovery by sterilization on the fatigue life and crack formation of Hyflex CM NiTi instruments. Material and Methods: the cyclic fatigue test was performed in two groups: In the first, it was continuously performed to establish the fatigue life (group $1, n=10)$; in the second, it was performed with outages of 30 s to evaluate cracks' nucleation and propagation (group $2, n=10$ ). The test was performed using a stainless steel canal that was $1.5 \mathrm{~mm}$ in diameter and $3.5 \mathrm{~mm}$ in depth, with an arc of $9.42 \mathrm{~mm}$ and radius of curvature of $6 \mathrm{~mm}$. The instruments were driven at $300 \mathrm{rpm}$. The fatigue time was recorded using a digital stopwatch (Technos). An electronic microscope (Quanta 250) was used to observe the crack formation and growth during the cyclic fatigue. Results: the autoclaved instruments endured $1196.67+214.63$ cycles, and the non-autoclaved endured 1000+199.42 cycles until the occurrence of fracture. The t-student test ( $\alpha=5 \%)$ revealed a significant difference. The cyclic fatigue test with pauses demonstrated a significantly longer cyclic fatigue life than the continuous cyclic fatigue test $(p<0.05)$. Conclusion: as revealed by SEM images, cracks grow with an increase in the number of cycles to fracture (NCF). It can be concluded that the shape of Hyflex CM instruments recovered by autoclaving withstood significantly more NCF than non-autoclaved instruments $(p<0.05)$, demonstrating an improvement of approximately $16 \%$.

Keywords: Endodontics; Autoclavage; Electron microscopy; Fatigue resistence; Control memory NiTi files.

\section{Introduction}

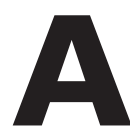
common complication inherent in the use of nickel-titanium instruments is their fracture, which can compromise the prognosis of canal treatment. ${ }^{1}$ Different NiTi alloys have been proposed to increase the flexibility and resistance to fatigue fracture of endodontic instruments. ${ }^{2,3}$ The Hyflex CM is one system that uses a controlled-memory alloy technology. These instruments are produced by thermomechanical treatment, resulting in more flexibility and greater resistance to fatigue. , $^{2,-6}$

Stress and temperature influence the mechanical properties of endodontic instruments manufactured using the NiTi alloy; they are sensitive to thermal cycles, which modify the microstructure. ${ }^{7}$ Some studies have investigated these effects in the M-wire, Phase-R, and controlled-memory NiTi alloys. ${ }^{8-10}$ The latter alloy, which was recently introduced in endodontics, has shown promising results. ${ }^{2,11}$ More studies are needed to investigate how these effects affect the controlled-memory NiTi alloy. The Hyflex CM manufacturer claims that the sterilization method enables reuse. However, further studies reporting the effects of mechanical cycling (fatigue) and heat (autoclaving) are needed to ensure that instruments are not re-used empirically.

Therefore, the aim of this study was to evaluate the influence of shape recovery by autoclaving on the number of cycles to fracture (NCF) and on the crack propagation of Hyflex CM endodontic instruments. The null hypothesis tested was that there are no differences in the cyclic fatigue fracture resistance between the instruments deformed and non-deformed plastically.

\section{- Instruments and Sterilization}

Twenty Hyflex CM (Coltene Whaledent, Cuyahoga Falls, OH, USA) instruments with a nominal size of $0.35 \mathrm{~mm}$ at D0, length of $25 \mathrm{~mm}$, and constant taper of $0.04 \mathrm{~mm} / \mathrm{mm}$ along the working length were used in this study. The instruments were randomly distributed with a free computer algorithm program (http://www. random.org) into two experimental groups ( $\mathrm{n}=10$ in each group).

Prior to the tests, the instruments were sterilized by autoclaving using a Cistofoli Vitale 12 (Cristofoli Biosafety equipment LTDA, Campo Mourão, PR, Brazil). Cycles had a holding temperature between $134^{\circ} \mathrm{C}$ and $137^{\circ} \mathrm{C}$ for 3 min. ${ }^{4}$ The instruments were sterilized before use, according to the manufacturer's instructions, and after each 30-s cycle of the cyclic fatigue test. These parameters comply with the requirements of the American National Standard/American Dental Association Specification No. 101. 2001, Root Canal Instruments: General Requirements.

\section{- Cyclic Fatigue Tests}

The cyclic fatigue test adopted the following procedures:

1. Group 1: ten instruments were subjected to the continuous cyclic fatigue test until fracture occurred, establishing the fatigue life without allowing instrument shape recovery.

2. Group 2: ten instruments were subjected to the cumulative cyclic fatigue test. The test was stopped after 30 s, and the instruments were autoclaved to recover their shape before a new test. This sequence of tests was performed until fracture occurred in all instruments. 


\section{- Continuous Cyclic Fatigue Test}

The cyclic fatigue test was performed using a custom-made device. ${ }^{10,12-15}$ The mounting rod allowed the fixation of the handpiece, which was regulated by a manual adjustment screw. The device allows vertical movement of the instrument in the longitudinal axis of the straight part of the metallic canal. A stainless steel AISI 316L metal canal, measuring $1.5 \mathrm{~mm}$ in diameter and $3.5 \mathrm{~mm}$ in depth, with an arc of $9.42 \mathrm{~mm}$ and radius of curvature of $6 \mathrm{~mm}$, was formed using computerized milling. The curvature radius of the canal was measured by taking into account the concave surface of the interior of the canal. The arc was located in the apical portion of the canal. ${ }^{14}$

The instruments were placed in the contra-angle gear unit and inserted into the channel so that its tip touched a shield positioned at the end of the arc. This shield aimed to standardize the distance of penetration of the instrument inside the channel and was removed after final adjustment of the instrument. During the test, the artificial canal was filled with glycerin to reduce the friction of the instrument against the canal wall and to minimize the release of heat. ${ }^{13,15}$ The time of fracture was recorded by the same operator using a digital stopwatch (Technos, Manaus, AM, Brazil). ${ }^{10}$ The total time was recorded and converted to NCF for subsequent statistical evaluation.

The instruments were driven by an engine (Satelec Endo Dual Motor; Acteon, Mérignac, France) at $300 \mathrm{rpm}$ and with a 16:1 reduction handpiece (W\&H, Dentalwerk, Bürmoos GMBH, Austria) at continuous rotation.

\section{- Cumulative Cyclic Fatigue Test}

The paused cyclic fatigue test simulated the use of the instruments recovered by sterilization. In the cumulative cyclic fatigue test, the same apparatus described previously was used. The engine was turned on for 30 s, the test halted, and the instruments that were not fracture were analyzed by SEM. Before resuming a new cycle of 30 s, the non-fractured instruments were sterilized. This procedure was repeated until the last instrument fractured.

Each cycle of $30 \mathrm{~s}$ corresponded to 150 rotations of the instrument inside the canal. The 30 -s cycles were summed up with the next step and the total time when fracture occurred $(\Sigma t)$ was calculated. The time was converted to NCF using the formula:

$$
\mathrm{NCF}=5 \times \Sigma \mathrm{t}
$$

\section{- Scanning Electron Microscopy}

The instruments were analyzed by SEM (Quanta 250 FEG, FEI, Oregon, USA) to check the surface finish provided by the manufacturer, and the fracture surface after the cyclic fatigue tests. ${ }^{10,12-15}$ Different magnifications were used $(300 \times-500 \times)$ to obtain photomicrographs at the point of maximum stress concentration (half the arc of $9.42 \mathrm{~mm}$ from the instrument end) to study the nucleation and propagation of cracks.

\section{- Statistical Analysis}

The preliminary analysis of the D'Agostino and Person omnibus normality test of the raw pooled and isolated data revealed data normality; therefore, statistical analysis was performed using parametric methods. The results were subjected to a Student's t-test. The alpha-type error was set at 0.05 . Origin 6.0 (Microcal Software, Inc, Northampton, MA) was used as an analytical tool. Data from fatigue tests were also subjected to statistical analysis proposed by Weibull to calculate the probability of the survival of the instruments according to usage of time.

\section{Results}

The data analysis demonstrated that Hyflex CM files revealed a significantly longer cyclic fatigue life when subjected to the $\mathrm{cu}-$ mulative cyclic fatigue test $(p<0.05)$. The means and standard deviations of the cyclic fatigue tests are shown in Table 1 . None of the files fractured during the first three cycles of the cumulative rotating bending test.

Table 1. Mean and Standard Deviation of Time and NCF for Fracture of HyFlex CM Instruments under Continuous and Cumulative Cyclic Fatigue test. Different superscript letters represent statistical differences $(p<$ $0.05)$

\begin{tabular}{l|c|c}
\hline \multicolumn{1}{c|}{ Test } & Time (s) & NCF* $^{*}$ \\
\hline $\begin{array}{l}\text { Continuous cyclic } \\
\text { fatigue }\end{array}$ & $120+23.93^{\mathrm{a}}$ & $1000+199.42^{\mathrm{a}}$ \\
\hline $\begin{array}{l}\text { Cumulative cyclic } \\
\text { fatigue }\end{array}$ & $143.6+25.75^{\mathrm{b}}$ & $1196.67+214.63^{\mathrm{b}}$ \\
\hline
\end{tabular}

* NCF is the number of cycles until the fracture occurs

The Weibull analysis showed that Hyflex CM instruments subjected to the continuous rotating bending test presented a lower probability of survival, according to the usage of the time (Figure 1).

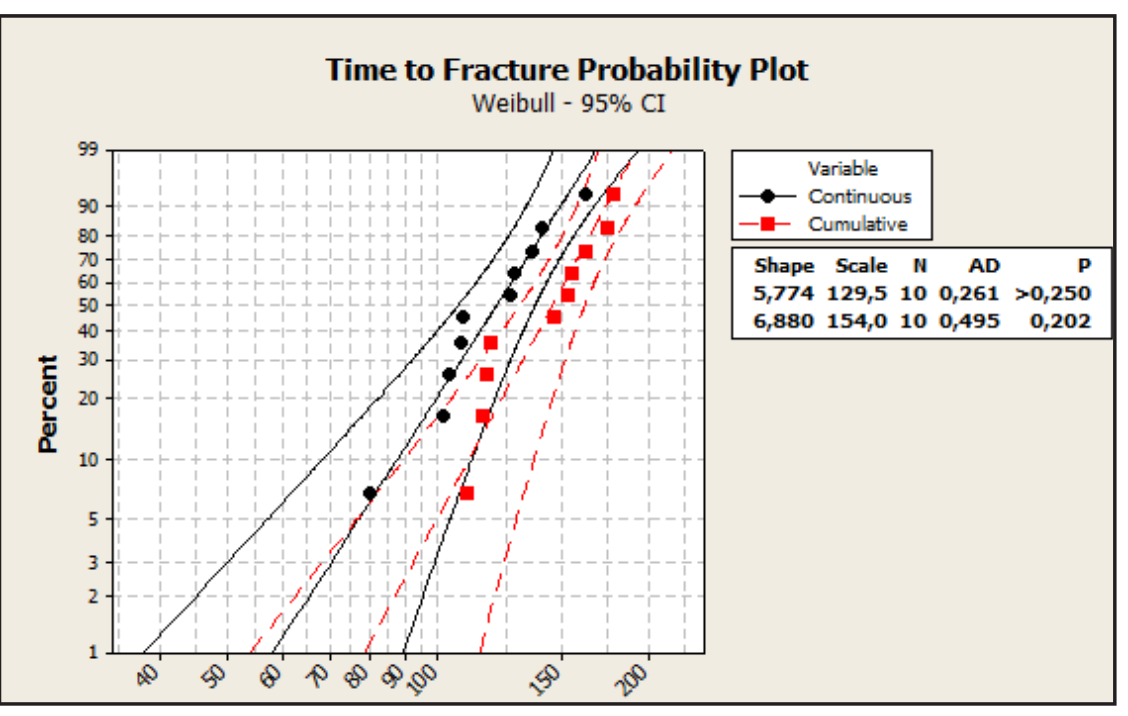

Figure 1. Weibull analysis of Hyflex CM instruments. The graph shows the probability of survival at continuous (black circles) and cumulative (red squares) fatigue tests.

SEM analysis revealed that all instruments displayed morphological characteristics of ductile fracture as found in other studies, ${ }^{10,12-15}$ regardless of the number of times the instrument was sterilized (Figure $2 \mathrm{~A}, \mathrm{~B}$, and C). It can be observed that the instruments subjected to a cumulative rotating bending test showed multiple cracks in the region corresponding to the center of the arc of the metallic artificial canal (Figure $2 \mathrm{D}$ ). With the 
advancement of the cumulative fatigue test, the size of the cracks increased (Figure $2 \mathrm{E}$ and F). Cracks could already be observed after the first stage of the cumulative rotating bending test (Figure $2 \mathrm{G}$ ), and they followed a definite pattern propagating through the contours of defects (Figure $\mathrm{H}$ and I). their findings, instruments whose shape was recovered by autoclaving exhibit greater fatigue life.

All instruments exhibit plastic deformation at the center of the arc of the artificial metallic canal used in the rotary bending tests, a region where cracks occurred due to stress concentration (Fig-

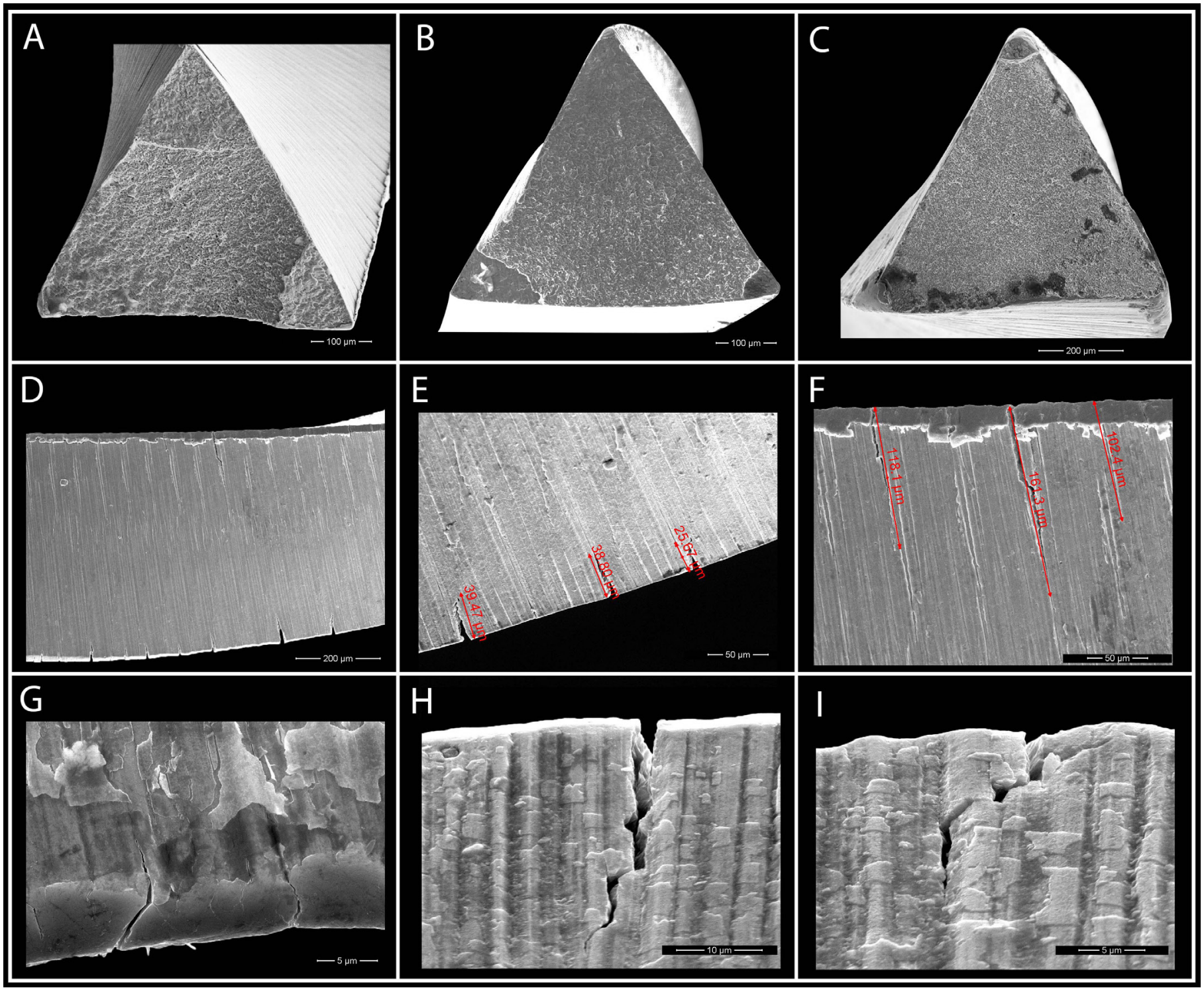

Figure 2. Fracture surface of instruments showing morphological characteristics of the ductile type. Instruments autoclaved two (A), three (B), and four (C) times (original magnification of 500x). Multiple cracks in the region corresponding to the center of the arc of the canal (D) (original magnification of $350 \times$ ). Cracks after 60 (E) and 90 (F) s of cycling (original magnification of $1000 \times$ ). Cracks observed after the first stage of the bending test $(\mathrm{G})$ (original magnification of $10000 \times$ ). Pattern of crack propagation and surface finishing of Hyflex CM instruments under magnification of $7000 \times(\mathrm{H})$ and $11000 \times(\mathrm{I})$

\section{Discussion}

The instruments' surface fractures showed a morphological aspect of ductile fracture. There was no difference in the surface appearance of instruments autoclaved two, three, or four times (Figure $2 \mathrm{~A}, \mathrm{~B}$, and $\mathrm{C}$, respectively). This is in accordance with the results found in other studies. ${ }^{10,12-15}$

Studies reported that not all Hyflex CM instruments regained their original shape after autoclaving., ${ }^{4,16}$ The inability to regain shape can be associated with altered metallurgical properties of the deformed instruments. ${ }^{3}$ The manufacturer recommends discarding instruments with reverse unwinding, ${ }^{17}$ in keeping with ure $2 \mathrm{D}$ ). Studies on the deformation rate are contradictory; they vary from $3.4 \% 3$ to $82 \%,{ }^{18}$ with some as high as $90 \% .{ }^{16}$ This can be attributed to the different models used in the studies.

The length of cracks increased with the time of the cyclic fatigue test. They nucleated in defects that originated from the manufacturing process at the top of the margins of the side cutting edges and propagated to the surfaces (walls) of the helical channels. After $60 \mathrm{~s}$ of cycling, the size of the cracks was in the range of 25-40 $\mu \mathrm{m}$ (Figure $2 \mathrm{E}$ ). After $90 \mathrm{~s}$ of fatigue, the cracks increased to $102-160 \mu \mathrm{m}$ (Figure $2 \mathrm{~F}$ ). Even at low levels of fatigue, cracks are present and can be observed in high magnifications; in this study, 
they could be detected at a magnification of $10000 \times$ (Figure $2 \mathrm{G}$ ).

The surface finishing defects can influence NCF. The irregularities serve as points for stress concentration and crack initiation. ${ }^{12}$ Under magnifications above $2000 \times$, the surface finish revealed an aspect similar to "fish scales", with square plates side by side. The cracks propagated, guided by the outline of these defects (Figure $2 \mathrm{H}$ and $\mathrm{I}$ ).

The discussion about the impact of autoclaving on fatigue life of NiTi instruments is contradictory in the literature. One study ${ }^{19}$ reported that there is no difference between sterilized and non-sterilized instruments made using the CM alloy, but another study ${ }^{6}$ showed that sterilization extended the cyclic fatigue life of these instruments and the cyclic fatigue life time increased approximately to $16 \%$, which corroborates this presented study.

The analysis of survival of the instruments as a function of testing time demonstrated that the continuous cyclic fatigue test ex- hibited a greater probability of fracture (Figure 1). Consequently, the autoclaved instruments presented a higher survival probability. The recovery of the original shape allows a better distribution of the stresses during the rotating bending test, which increases NCF of the instruments.

\section{Conclusion}

As revealed by SEM images, cracks grow with the increase in NCF. It can be concluded that the shape of Hyflex CM instruments recovered by autoclaving presented significantly more NCF than non-autoclaved instruments $(p<0.05)$, demonstrating an improvement of approximately $16 \%$.

\section{Acknowledgments}

The authors acknowledge the Brazilian agency FAPERJ for financial support (E-26/203.313/2016 - Young Scientist of Our State).

\section{References}

1. Ankrum MT, Hartwell GR, Truitt JE. K3 Endo, ProTaper, and ProFile systems: breakage and distortion in severely curved roots of molars. J Endod. 2004;30(4):234-7.

2. Uygun AD, Kol E, Topçu MK, Seckin F, Ersoy I, Tanriver M. Variations in cyclic fatigue resistance among ProTaper Gold, ProTaper Next and ProTaper Universal instruments at different levels. Int Endod. 2016;49(5):494-9.

3. Shen Y, Coil JM, Zhou H, Zheng Y, Haapasalo M. HyFlex nickel-titanium rotary instruments after clinical use: metallurgical properties. Int Endod J. 2013;46(8):720-9.

4. Alazemi MA, Bryant ST, Dummer PMH. Deformation of HyFlex CM instruments and their shape recovery following heat sterilization. Int Endod J. 2015;48(6):505-626.

5. Plotino G, Testarelli L, Al-Sudani D, Pongioni G, Grande NM, Gambarini G. Fatigue resistance of rotary instruments manufactured using different nickel-titanium alloys: a comparative study. Odontology. 2014;102(1):31-5.

6. Zhao D, Shen Y, Peng B, Haapasalo M. Effect of autoclave sterilization on the cyclic fatigue resistance of thermally treated Nickel-Titanium instruments. Int Endod J. 2015;Epub ahead of print. doi: 10.1111/iej.12550.

7. Thompson, SA. An overview of nickel-titanium alloys used in dentistry. Int Endod J. 2000;33(4):297-310.

8. Shen Y, Riyahi AM, Campbell L, Zhou H, Du T, Wang Z, et al. Effect of a Combination of Torsional and Cyclic Fatigue Preloading on the Fracture Behavior of K3 and K3XF Instruments. J Endod. 2015;41(4):526-30.

9. Pedullà E, Grande NM, Plotino G, Gambarini G, Rapisarda E. Influence of continuous or reciprocating motion on cyclic fatigue resistance of 4 different nickel-titanium rotary instruments. J Endod.2013;39(2):258-61.

10. Lopes HP, Soares TG, Elias CN, Siqueira JF, Inojosa IFJ, Lopes WSP, et al. Comparison of the Mechanical Properties of Rotary Instruments Made of Conventional Nickel-Titanium Wire, M-Wire, or Nickel-Titanium Alloy in R-Phase.
J Endod. 2013;39(4):516-20.

11. Hieawy A, Haapasalo M, Zhou H, Wang ZJ, Shen Y. Phase Transformation Behavior and Resistance to Bending and Cyclic Fatigue of ProTaper Gold and ProTaper Universal Instruments. J Endod. 2015;41(7):1134-8.

12. Lopes HP, Elias CN, Vieira VTL, Moreira EJL, Marques RVL, Oliveira JCM, et al. Effects of Electropolishing Surface Treatment on the Cyclic Fatigue Resistance of BioRace Nickel-Titanium Rotary Instruments. J Endod. 2010;36(10):1653-7.

13. Rodrigues RCV, Lopes HP, Elias CN, Amaral G, Vieira VTL, De Martin AS. Influence of Different Manufacturing Methods on the Cyclic Fatigue of Rotary Nickel-Titanium Endodontic Instruments. J Endod. 2011;37(11):1553-7.

14. Lopes HP, Vieira MVB, Elias CN, Gonçalves LS, Siqueira Jr JF, Moreira EJL, et al. Influence of the Geometry of Curved Artificial Canals on the Fracture of Rotary Nickel-Titanium Instruments Subjected to Cyclic Fatigue Tests. J Endod. 2013;39(5):704-7.

15. De-Deus G, Vieira VTL, Silva EJ, Lopes HP, Elias CN, Moreira EJ. Bending resistance and dynamic and static cyclic fatigue life of Reciproc and WaveOne large instruments. J Endod. 2014;40(4):575-9.

16. Bürklein S, Börjes L, Schäfer E. Comparison of preparation of curved root canals with Hyflex CM and Revo-S rotary nickel-titanium instruments. Int endod J. 2012;47(5):470-6.

17. Coltene Endo Hyflex Family Brochure. [PDF on Internet] [accessed on October 2015] Avaliable from: http://www.hyflexcm.com/DevDownloads/HyFlexFamily_bro.pdf.

18. Peters OA, Gluskin AK, Weiss RA, Han JT. An in vitro assessment of the physical properties of novel Hyflex nickel-titanium rotary instruments. Int endod J. 2012;45(11)1027-34.

19. Casper RB, Roberts HW, Roberts MD, Himel VT, Bergeron BE. Comparison of Autoclaving Effects on Torsional Deformation and Fracture Resistance of Three Innovative Endodontic File Systems. J endod. 2011;37(11):1572-5.

\section{Mini Curriculum and Author's Contribution}

1. Victor Talarico Leal Vieira - DDS and PhD. Contribution: manuscript writing, fatigue tests, electronic microscopy and paper submission.

2. Hélio Pereira Lopes - DDS and PhD. Contribution: work supervisor, manuscript writing, bibliographical research and fatigue test.

3. Carlos Nelson Elias - PhD. Contribution: electronic microscopy and manuscript review.

4. Leticia Chaves de Souza - DDS and PhD. Contribution: fatigue tests and manuscript review.

5. Emmanuel João Nogueira Leal da Silva - DDS and PhD. Contribution: manuscript writing and review.

6. Daniel de Brito Prata - DDS. Contribution: bibliographical research and image editing.

7. Edson Jorge Lima Moreira - DDS and PhD. Contribution: statistical analysis.

8. Marcia Valeria B. Vieira - DDS and PhD. Contribution: fatigue tests and instruments autoclavage.

Submitted: 11/15/2016 / Accepted for publication: 02/10/2017

Corresponding Author

Victor Talarico Leal Vieira

E-mail: victortalarico@unigranrio.edu.br 